\title{
2
}

\section{Triangulating Faculty Needs for the Assessment of Student Learning}

\author{
D. Lynn Sorenson \\ Timothy W. Bothell \\ Brigham Young University
}

To enhance assessment of student learning, the Brigham Young University (BYU) Faculty Center undertook a needs assessment to guide new initiatives. Researchers reviewed results from the National Survey of Student Engagement and an earlier BYU faculty survey. In addition, they conducted a qualitative study with faculty and administrators. The qualitative study can serve as a model for other faculty developers considering new initiatives. The findings raised thought-provoking issues for faculty development, particularly faculty readiness. As a result of this research, the center bolstered current services and developed new ones to support the assessment of student learning.

\begin{abstract}
A ssessment of student learning is a critical part of teaching. Yet, as integral as it is to teaching and learning, it is often ignored in development efforts. In a study at Georgia State University (Commander, Hart, \& Singer, 2000), faculty named student performance as the most important indicator of good teaching. However, this study (and others) focuses little on what faculty need to effectively assess student performance. How can good teaching and learning be achieved if the needs of faculty for effective assessment are neither known nor met?
\end{abstract}

\section{BACKGROUND}

Most new faculty developers-and most new faculty development centersundertake a (faculty) needs assessment as one of their first endeavors. Travis, Hursh, Lankewicz, and Tang (1996) identified "relatively inadequate coverage 
of this all-important topic [needs assessment] ... in the available literature..." (p. 96). Travis et al. sought to remedy this lack by documenting models and processes for faculty development needs assessment at four institutions: East Texas State University, West Virginia University, University of South Alabama, and The Ohio State University. A 1993 East Texas survey identified constructing effective exams as an area of high interest.

Travis et al. (1996) suggested "to best monitor the pulse of the faculty, needs assessment should be conducted on a continuous, timely basis with variable approaches being used for data collection" (p. 96). They further suggested that "the survey instrument seems to be the weakest link [in needs assessment, favoring instead the] information-rich interview technique" (p. 107).

In the qualitative study documented in this chapter, the researchers at the ten-year-old Brigham Young University (BYU) Faculty Center decided to get more serious about following up on two of the most useful sources for ascertaining the current state of student learning: the National Survey of Student Engagement-the College Student Report 2000 (NSSE) and a campus-wide survey, the BYU Faculty Assessment Activity Study, 1999-2000 Academic Year (FAAS). The NSSE provided a student perspective from which the researchers determined some related faculty development needs. In addition, the FAAS provided a relevant faculty perspective. Shortly after hiring a new faculty center professional-and before he became overwhelmed with new duties-this qualitative study was launched in 2001 . It examined faculty needs, perceptions, and issues about the assessment of student learning.

\section{The Status of Assessment}

The following is a brief summary of key findings from the NSSE and FAAS.

\section{Frequency of Student Assessment (From NSSE)}

Most faculty evaluate student learning at least every two weeks; however, onefifth do so only once a month at best. The colleges that reported assessing most frequently were:

- Nursing

- Humanities

- Education

- Physical and mathematical sciences 


\section{Methods Used to Assess Student Learning (From NSSE)}

BYU faculty tend to use more multiple-choice exams with freshmen than faculty at other institutions (see Figure 2.1). A discrepancy exists between the assessment methods faculty reported using most often (e.g., exams, class presentations, quizzes, group projects) and the methods they felt were most effective (e.g., field work, capstone projects, performances).

FIGURE 2.1

\section{NSSE Findings Concerning Types of Exams}

In the National Survey of Student Engagement (NSSE), students were asked about the types of exams they take most often.

There were 276 participating four-year colleges and universities with 151,910 student responses (from BYU there were 1,500 students).

Rating Scale: 1 = Mostly Multiple-Choice or Short Answer

7 = Mostly Essay or Open-Ended Problems

\begin{tabular}{lccc}
\hline MEANS & $\begin{array}{c}\text { BYU } \\
\text { (Research I) }\end{array}$ & $\begin{array}{c}\text { R. I \& II NSSE } \\
\text { Institutions }\end{array}$ & $\begin{array}{c}\text { Natl. Averages } \\
\text { All NSSE Schools }\end{array}$ \\
\hline Freshman & $\mathbf{2 . 8 8}$ & 3.35 & 3.79 \\
Seniors & $\mathbf{4 . 2 3}$ & 4.29 & 4.42 \\
\hline
\end{tabular}

Aside from writing assignments, most faculty employed assessment tools they rated as being less effective. These phenomena may occur because faculty select assessment methods based on practical issues (e.g., time required to develop, time required to grade, ease of use by students) rather than basing their choices on (either the perceived or actual) effectiveness of the methods for assessing student learning.

Figure 2.2 shows two graphs which represent the methods faculty used most frequently (in the graph on the left) and their opinions about the effectiveness of each method (in the graph on the right). 
FIGURE 2.2

Discrepancy Between Faculty Methods and Faculty Beliefs

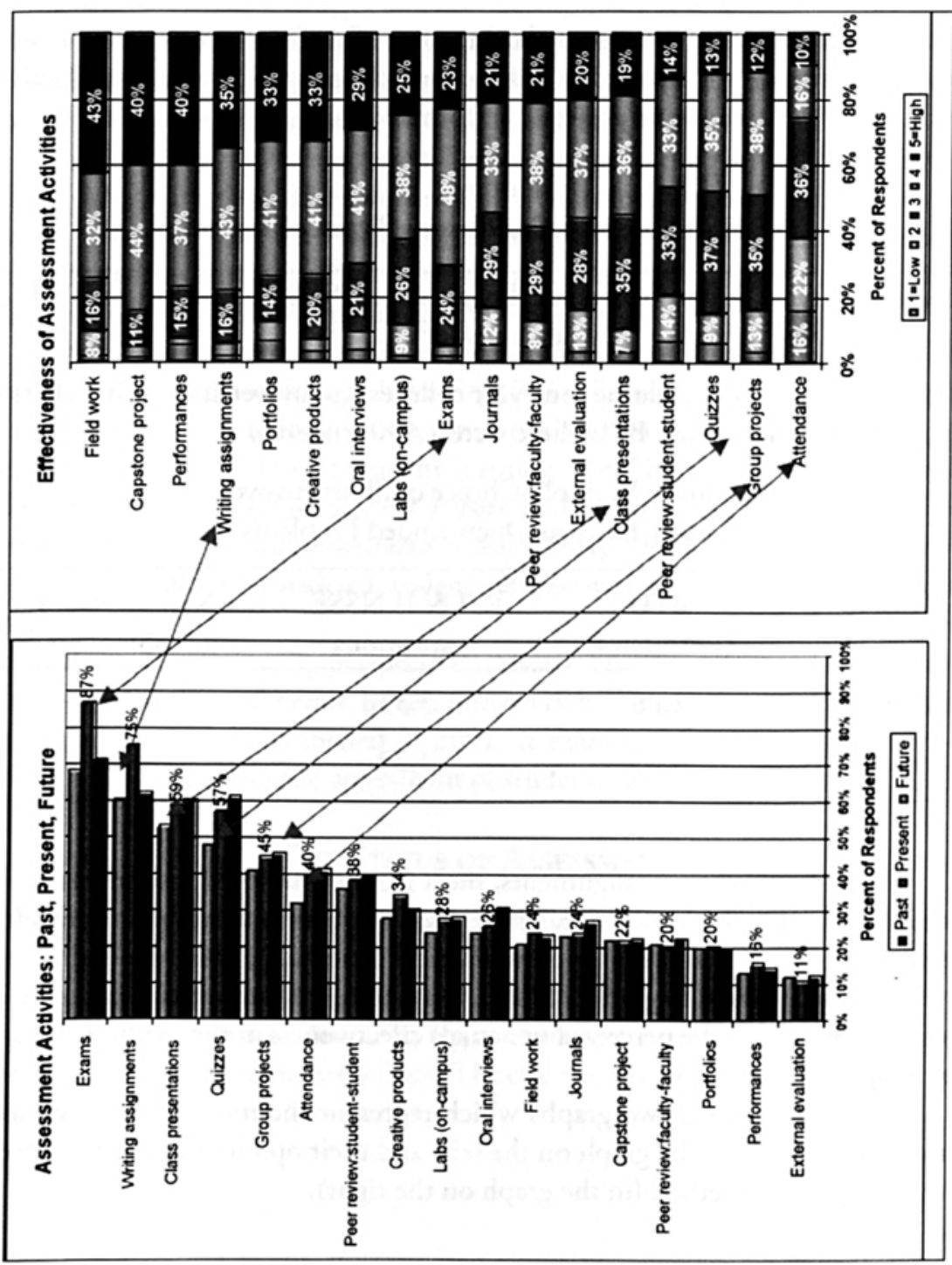


The methods on the left are listed in order of frequency of use with the most frequent at the top. On the right, the faculty perceptions of effectiveness are listed with the methods perceived most effective at the top. The arrows between the two graphs highlight the discrepancy between frequency of use and perceived effectiveness. In other words, the methods of assessment that faculty deem least effective are the methods that they use most.

\section{Development Needs Suggested by National Survey of Student Engagement (NSSE)}

The NSSE suggested several areas for consideration: learning to assess and grade student learning, both effectively and efficiently; and the use of midcourse feedback for improvements during a course.

Effectiveness of assessments. According to the NSSE results, BYU faculty often viewed assessment as something they do "to" students rather than something they do "for" students (or for themselves). In addition, faculty viewed the assessment of student learning as a way to confront student understanding, knowledge, and effort. Few faculty viewed assessment of student learning as a tool for determining the effectiveness of the course or the teacher, in contrast with the Georgia State University faculty who saw it as the primary indicator of good teaching.

Again, faculty felt they were effective in assessing student learning, yet they reported that the methods they use most frequently are the methods they feel are less effective. Approximately 12\% of BYU faculty reported that their current plan for assessing student learning is "ineffective." This could suggest that approximately 200 faculty members and approximately 18,000 students experience ineffective assessment every semester (assuming each faculty member has 30 students per class and three classes per semester).

The colleges that reported the highest percentage of ineffective assessment plans were:

- Religious education

- Engineering and technology

- Biology and agriculture

- Law

- Fine arts and communication

- Family, home, and social science 
Grading. Assessment of student learning is inexorably linked to grading. More BYU faculty grade on a fixed standard of performance (criterion-referenced) than on a class curve (norm-referenced). The colleges of nursing, education, religious education, and health and human performance do the most criterion-referenced grading.

Mid-course evaluations. According to the NSSE, more than half of the BYU faculty who administer mid-course evaluations make mid-course adjustments. Colleges that reported the most faculty making mid-course adjustments were:

- Fine arts and communications

- Engineering and technology

- Education

\section{Development Needs Suggested by Faculty Assessment Activity Study (FAAS)}

In general, the FAAS suggested that faculty would like more support and resources to improve assessment in their courses. Development needs included assessment of critical thinking, test design issues, classroom assessment techniques, as well as understanding factors that impact student learning.

In choosing from a list of alternatives on the FAAS, respondents most frequently requested support for the assessment of critical thinking, followed by the construction of reliable and valid tests. Curriculum development was the least requested training topic, perhaps because the term was not well understood by most disciplinary faculty. Educationists understand that curriculum development includes not only content issues, but also evaluating and (re)writing objectives, developing more effective learning activities, designing appropriate assessments, and aligning assessment to objectives. However, many noneducationist faculty are unfamiliar with the term "curriculum development." They may believe that it includes only content issues (for which they feel no need for help) or they fail to understand the term at all. This may explain why BYU faculty declined asking for help with curriculum development.

Results from the FAAS showed that when given a list of ways to improve the effectiveness of their assessments, faculty selected "TA help" most frequently, followed by "understanding factors that influence student learning." "Technology support" was listed third, and "training" was fourth. 
The colleges with the highest number of requests for assessment support were:

- Religious education

- Nursing

- Law

- Humanities

- Health and human performance

With regard to assessing student learning with technology, FAAS revealed that faculty were requesting additional technology support that could be provided by teaching assistants or other technology support staff. Faculty also requested funds for these kinds of endeavors. Half of the faculty would consider having their classroom exams administered online in the testing center and the College of Nursing and the College of Family, Home, and Social Sciences had the most interest in online testing.

\section{Interviewing Faculty to Discern Needs and Priorities}

Since 1992, the Brigham Young University Faculty Center has supported faculty with many developmental services and has recently increased its focus in the area of assessment.

This qualitative research was a part of the center's increased emphasis on assessment. To avoid spending time on unnecessary or marginal activities, it was important to hear from faculty themselves about their perceived needs in assessing student learning. The study was not an extensive research project with a large sample size, but rather a small, quick study designed to measure common responses and identify basic themes common to BYU faculty.

\section{The Interview Questions}

1) What do faculty need in the area of assessing student learning?

2) What can be done to assist faculty with their needs in assessing student learning?

3) What challenges related to assessing student learning should faculty developers be concerned about?

4) What should be done first (receive highest priority) to assist faculty in the assessment of student learning? 
5) Who else on campus should be worked with to improve the assessment of student learning?

6) How should department chairs and deans be involved with improving the assessment of student learning?

The interviews were conducted on campus in faculty members' offices. On average, it took about an hour to complete each interview. Most faculty wanted to hear all six questions before answering any of them. They then spent the majority of the time answering Question 1. In many instances, faculty answered the other five questions while answering the first question. During the interviews, the researcher took notes that were later analyzed and developed into action items.

\section{The Sample}

Forty-two faculty were interviewed, five of whom were also serving as administrators at that time. This provided insight from both faculty and administrator perspectives.

Faculty participants were recom mended for the interviews by administrators and by faculty developers at the Brigham Young University Faculty Center. During the interviews, some participants suggested additional faculty for the study. In general, the names recommended were faculty members who had reputations as good teachers and/or as effective learning assessors. Table 2.1 illustrates the departments and colleges involved.

\section{INTERVIEW Findings}

Armed with the results of the NSSE and FAAS, the researchers developed analyses and conclusions from the $\mathbf{4 2}$ faculty interviews.

\section{Faculty Needs (Question 1): What Do Faculty Need in the Area of Assessing Student Learning?}

The first question that faculty and administrators were asked during the interviews required each individual to think about faculty needs across the entire campus. This approach seemed appropriate since the names provided for the interviews were individuals who had reputations for being effective at assessing student learning. In addition, focusing on the needs of the university as a whole was a strategy designed to help the participants feel less threatened and more comfortable - the interviewees felt no pressure to reveal their own personal nceds or weaknesses, but were encouraged instead to think about their colleagues' assessment needs. 
TABLE 2.1

Percentage of Sample by Department or Role

\begin{tabular}{ccl}
\hline Number & Percentage & Department/Role \\
\hline 5 & $12 \%$ & $\begin{array}{l}\text { Administration } \\
\text { Center for Instructional Design (creates online } \\
\text { courses and modules for hybrid courses) }\end{array}$ \\
1 & $10 \%$ & Department of Chemistry \\
1 & $2 \%$ & Department of Communications \\
1 & $2 \%$ & College of Education \\
1 & $2 \%$ & College of Engineering \\
6 & $14 \%$ & BYU Faculty Center \\
2 & $5 \%$ & College of Fine Arts and Communications \\
2 & $5 \%$ & General Education and Honors \\
3 & $7 \%$ & College of Humanities \\
4 & $10 \%$ & Department of Instructional Psychology and \\
& & Technology \\
3 & $7 \%$ & Independent Study \\
2 & $5 \%$ & School of Music \\
2 & $5 \%$ & Office of Institutional Assessment and Analysis \\
4 & $10 \%$ & Religious Education \\
1 & $2 \%$ & Testing Services \\
\hline
\end{tabular}

Some responses to this question were different from the findings of the NSSE and FAAS. For example, the FAAS found "TA support" was the most requested assessment need, followed by "understanding factors that influence student learning," and then, "technology support." Yet, faculty interviewed mentioned "training" more frequently than any other need. This may be because the interviews focused on the needs of faculty across the entire university. The FAAS asked faculty about their own personal needs, rather than the needs of generic "faculty." Therefore, the FAAS responses tended to be more specific (e.g." "TA support") than the generic responses of the 2001 interviews (e.g., "training"). 
The three most frequent responses to this first interview question were:

- Training

- Feedback on exams

- Support to align learning outcomes, instruction, and assessment

In some instances during the interviews, faculty mentioned training and provided specific examples of the topics they suggested for the training. Other times, they would mention training without providing topic ideas. Even after additional probing questions were asked, some faculty could not articulate what type of training was needed.

Even though some faculty see a need for assessment training and support, many lack understanding of what that training might entail. They may have concerns (arising from student evaluations or from peer faculty feedback) that suggest a need for training, but they don't know the assessment issues well enough to state what specific training is necessary.

However, the very few faculty who did provide specific examples tended to brainstorm long lists of ideas for assessment training:

- Practice writing test questions

- Practice choosing appropriate methods

- Support determining outcomes or what they hope students will accomplish

- Make assessment meaningful, "full of heart," and "authentic"

- Align course objectives with assessment

- Create challenging tests

- Decide on a discrimination approach or a mastery approach

- Develop assessments that help students have a learning experience during the exam ("effective assessment enhances a love of learning")

- Help students do self-assessment ("an educated person should be really good at self-assessment")

- Assess students' higher-order thinking skills

- Control grade inflation 
- Place more emphasis on formative evaluation to make mid-course changes to improve learning

- Motivate students intrinsically through assessment

- Move assessment to a criterion-referenced system

- Integrate mission of BYU into assessment

- Account for long-term goals of students when planning assessment

- Get students to desire feedback and to take responsibility for their own learning

- Write multiple-choice questions in a way that tests for application

- Test online

It is clear from this list of examples that faculty training needs can be varied in the area of assessing student learning. Since faculty needs are diverse, it may be difficult to narrow the topics for support on assessing student learning (e.g., for workshops). In order to meet diverse needs, assessing student learning may be an area of faculty development that requires more one-on-one consultation than group instruction.

The second most frequent response given to the first interview question was "feedback to improve exams." Many faculty wanted to know if there was a central service or location on campus where exams could be safely left for review and feedback. Most knew where to take their writing projects for review and feedback, and expressed a desire for a similar place to take their exams. They wanted someone to look at their test questions to determine if they were meaningful, clear, valid, reliable, and grammatically correct. Some wanted detailed item analyses to help them decide which items needed revision and which should be removed from their exams.

The third most frequent response to the first interview question on faculty needs was about alignment of course components. Faculty reported a need for support to align learning outcomes, instruction, and assessment. This was an interesting response because the interviewees acknowledged the need for improved alignment but declined help with course design and objectives. When asked what support was needed, faculty frequently reported a campus-wide need for help in the alignment of course components. Yet, when asked directly in follow-up questions about their own course objectives or course design, the faculty interviewees declined support and were hesitant to discuss it further. 
As noted in the FAAS findings, the researchers hypothesize that many faculty (noneducationists) believe that course design and curriculum development are solely content issues. Most feel secure in their content knowledge and expertise; hence, most did nor request support in course design. Nevertheless, assessment is an important part of course design and curriculum development. Perhaps faculty fail to understand the integral connection of assessment to course design, instead considering assessment as a component of a course that can be inserted, improved, or removed without relation to other course components. Perhaps they see "alignment" (among objectives, activities, and assessment) as an activity different from course design. This incongruency may present a challenge for faculty developers.

Another interesting finding was that administrators had stronger feelings than faculty about the need for effective course design. Administrators talked about improving the assessment of student learning in terms of redesigning all components of a course and aligning the components to each other. Faculty talked about assessment as if it were disconnected from other components of the course. This was not always the case, but it is interesting to note differences in their perspectives.

Less frequently mentioned responses about faculty needs included:

- Provide more time for teaching in class by assessing out of class

- Provide training to build an effective environment for testing

- Provide training about grading issues (e.g., how to control grade inflation, weighting exams versus assignments, using grading rubrics, training on how to do online submission of grades)

- Support for designing multiple forms of exams

- Support with pre-test assessment to assess student readiness

- Provide handouts, resources, and articles

- Provide training about using work experience, capstone experience, field work as major assessments

\section{Assist Faculty (Question 2): What Can Be Done to Assist Faculty With Their Needs in Assessing Student Learning?}

The three most common responses to this interview question were:

- Provide one-on-one consulting support

- Work with department chairs and deans to establish collaborative efforts 
- Provide an exam service where faculty can get feedback and suggestions to improve their exams

Obviously, there is some overlap between the most frequent responses provided to interview Question 1 and those provided to interview Question 2. In response to both interview questions, faculty mentioned the need for feedback to improve exams. This was a recurring theme throughout all of the interviews, and underscores a strong need to provide faculty with this feedback.

Faculty also mentioned "training/workshops" in answer to both questions, although for Question 2, training was not in the three most frequent responses. This indicates a perception by faculty that one-on-one consulting may be more useful for their improvement needs than workshops on assessing student learning. This perception may not be shared by all faculty, but the most common response reported was assisting faculty with their assessment needs through "one-on-one consulting."

Almost every administrator emphasized the importance of working with department chairs and deans to establish collaborative efforts. They were more interested in this than were the faculty interviewees. Faculty rarely mentioned the idea of working with colleagues to improve the assessment of student learning. When administrators mentioned collaborative efforts led by department leaders, they spoke about accreditation, research grants, fellowships, large classes, and multiple sections of the same course with several teachers. Administrators may have wanted collaborative work teams because of their perspectives (and pressures) at the department and college level.

Some of the less frequently mentioned responses to Question 2 about assisting faculty included:

- Teach the consequences of ignoring the problem of poor assessment

- Share examples of success

- Connect web resources and announce Brigham Young University Faculty Center offerings on several web pages

- Make faculty aware of misalignment between their course components (objectives, activities, and assessment)

- Find differences among departmental needs

- Designate a testing expert for each college 
Challenges (Question 3): What Challenges Related to Assessing Student Learning Should Faculty Developers Be Concerned About?

The most frequent responses to this question included:

- Lack of resources to support faculty with assessment

- Lack of time (faculty are too busy)

- Philosophies and approaches to grading

- Independence (faculty want flexibility and freedom to "do their own thing")

When discussing the issue of resources and time, faculty inevitably brought up their roles at the university-research, teaching, and citizenship. Some discussions about the issue of balancing these roles were typically very passionate and even somewhat disconcerting. Administrators advise faculty to balance scholarship, citizenship, and teaching, and faculty were very conscious of the difficulties in doing that. Many faculty members questioned how they could worry about improving assessment when they had so many demands on their time. Whether it was an issue of busyness, lack of resources (TAs, faculty developers, time with other colleagues), or pursuit of their research interests, the difficulties all seemed to be about competing priorities.

Many faculty members (but not administrators) mentioned grading philosophies as a challenge to improving the assessment of student learning. They stated that some philosophies of grading required challenging, even "tricky," assessment. This type of assessment purposely causes a portion of students to fail. This approach can present obstacles and can be an interesting challenge for the task of improving assessment of student learning.

Other less frequently mentioned responses to Question 3 were:

- Large classes

- TA training

- Complacent faculty

- Grade inflation

- Assessments not authentic

- Lack of feedback to students 
Highest Priority (Question 4): What Should Be Done First (Receive Highest Priority) to Assist Faculty in the Assessment of Student Learning?

The most frequent response to this question was simply to educate faculty concerning what resources are available to support them with the assessment of student learning. Faculty were often pleasantly surprised to hear that a faculty developer had been assigned to the task. And they were typically unclear about what other resources were available to assist them.

Some of the less frequently mentioned responses included:

- Develop a stronger voice/advocacy for learning and teaching across campus

- Make workshops practical-hands-on and practice oriented

- Start where the complaints are (as per student evaluations)

- Work on courses with high failure rates to improve exams

- Find and work with good practitioners of effective assessment procedures

Working Together (Question 5): Who Else on Campus [besides the BYU Faculty Center] Should Be Worked With to Improve the Assessment of Student Learning?

The most frequent responses given to this question were:

- Center for Instructional Design

- Undergraduate education

- Assessment experts

- Testing services

- Graduate studies

- Independent study

Almost all of these units provide services that assist faculty with instructional design issues. 


\section{Administrator Involvement (Question 6): How Should Department Chairs and Deans Be Involved With Improving the Assessment of Student Learning?}

The most frequent responses to this question were also the only responses to this question:

- Educate them [the administrators]

- Ask them for names of faculty interested in working on assessment

- Provide incentives to faculty (release time, funding for student assistants)

Most of the administrators stated that they had not participated in any of the above three activities.

\section{SUMmary OF 2001 Findings}

This study was not meant to be an exhaustive research project to discover with irrefutable evidence all of the needs of faculty in the area of assessing student learning. It was meant to be a quick probe into the minds of faculty and administrators concerning the issue. At least five simple conclusions are proffered from this inirial study:

1) The methods BYU faculty use most often for assessing student learning are not always those they believe to be most effective.

2) Faculty want training in the area of assessment.

3) Improvement in assessing student learning is sought through one-onone consulting.

4) Faculty request specific feedback and suggestions on their exams.

5) Faculty needs were varied (e.g., testing through technology, grade inflation, pre-testing, self-assessment). Thus, faculty developers should prepare themselves for a wide range of issues and activities relating to the improvement of assessing student learning.

These findings point to a strong need-and a strong desire-for faculty development in the area of assessing student learning, especially because faculty often do what they feel is less effective. Also, these findings indicate a need for faculty development that cannot be met solely through workshops, but also through one-on-one consulting (which may be preferred). The requests related to one-on-one consulting were diverse and will require assessment expertise. 
Thus, faculty development units desirous of increasing their assessment support should increase their own assessment expertise.

\section{Conclusion}

As a result of the triangulation of these three studies (NSSE, FAAS, and the 2001 interviews), the Brigham Young University Faculty Center has increased its emphasis on faculty development efforts designed to improve assessment of student learning. To this end, the center initiated the following:

- One-on-one consultations for the improvement of exams (with individual faculty and with administrators)

- Workshops (e.g., assessing more than recall, increasing learning when returning exams, polishing the use of multiple-choice questions, writing effective essay questions, assessing for learning)

- College and department presentations

- Review of items about exams on student evaluations

- Training of student assistants to give exam improvement feedback

- Collaborative, department-specific efforts to improve exams for multisection courses

- Design and development of self-directed guidebooks for improving tests 


\section{REFERENCES}

Commander, N. E., Hart, L., \& Singer, M. (2000). Preparing tomorrow's faculty: An assessment model to determine institutional needs. The Journal of Graduate Teaching Assistant Development, 72), 93-111.

Travis, J. E., Hursh, D., Lankewicz, G., \& Tang, L. (1996). Monitoring the pulse of the faculty: Needs assessment in faculty development programs. In L. Richlin \& D. DeZure (Eds.), To improve the academy: Vol. 15. Resources for faculty, instructional, and organizational development (pp. 95-113). Stillwater, OK: New Forums Press.

\section{Contact:}

D. Lynn Sorenson

Brigham Young University Faculty Center for Teaching Excellence 4450 WSC

Brigham Young University

Provo, UT 84602

Voice (801) $422-7420$

Fax (801) 422-0223

Email lynn_Sorenson@byu.edu

Timothy W. Bothell

Faculty Development Coordinator

Brigham Young University

4450 WSC

Provo, UT 84602

Voice (801) 422-8194

Fax (801) 422-0223

Email tim_bothell@byu.edu

D. Lynn Sorenson, Assistant Director of the Brigham Young University Faculty Center, is serving her second term on the POD Core Committce. She has been involved in faculty development for more than a dozen years, starting at the University of Oklahoma. She holds degrees in English, Education, and Human Relations from (respectively) California State University at San Francisco, University of California at Berkeley, and the University of Oklahoma. She serves on boards of reviewers for Anker Publishing and New Forums Press.

Timothy W. Bothell is the Faculty Development Coordinator for the Assessment of Student Learning at Brigham Young University. He currently conducts workshops and works with faculty one-on-one to improve the assessment of student learning. He also directs the Exam Improvement Center within BYU's Faculty Center. Faculty from all colleges and departments are invited to leave their exams at the center for suggestions and ideas. In addition, as an independent consultant, he advises organizations concerning the return on investment (ROI) of learning. 